\title{
A importância das estatísticas como instrumento de construção da modernidade educativa no Brasil - décadas de 1930 e 1940
}

Palavras-chave: história da educação; estatísticas educacionais; imprensa periódica; discurso educacional.

\section{Resumo}

Busca recuperar o processo pelo qual as estatísticas educacionais afirmaram-se como instrumento privilegiado de orientação da gestão pública do ensino brasileiro, durante o governo Vargas. Para tanto, foram sistematizadas as iniciativas que resultaram na consolidação de um sistema nacional de coleta e análise das estatísticas de educação e descritas as funções atribuídas aos números nos discursos oficiais que circularam no período.

\section{Introdução}

A difusão da idéia de que a educação deveria ser oferecida a toda a população deu ensejo à expansão da "escola de massas", motivando o interesse em se conhecer quantitativamente o alcance da instituição escolar com relação ao efetivo populacional e imprimindo a necessidade de se estimar a demanda por ensino. Assim, a demografia, através das técnicas estatísticas, passou a responder por estudos acerca do movimento escolar que pudessem fornecer informações consideradas racionais e científicas com vista a adequadamente orientar decisões políticas para a educação. Na metade final do século 19, no Brasil, ainda que se afirmasse constantemente o papel das estatísticas na condução das ações de governo, destacavamse os debates acerca da necessidade de se aperfeiçoar o aparelho de coleta e tratamento dos dados quantitativos, de modo que os números eram utilizados com cautela. Nas décadas de 1930 e 1940, com a retomada das discussões sobre a ampliação das oportunidades escolares e contando-se com uma melhor estrutura para a produção das estatísticas de ensino, tais dados passam a desfrutar de maior credibilidade, figurando, portanto, nos discursos sobre educação, imbuídos de grande autoridade explicativa.
Assim, debates acerca do atendimento da demanda por educação, da oferta de vagas no ensino, da evasão e da repetência escolar, do analfabetismo, entre outros, foram freqüentemente conduzidos a partir de dados estatísticos que procuravam "retratar" as situações educacionais com recurso aos números. Também as justificativas para as insuficiências quantitativas do sistema escolar, bem como para as iniciativas governamentais na área da educação, eram muitas vezes indicadas e reforçadas a partir das cifras oficiais.

$\mathrm{O}$ presente texto procura recuperar o processo pelo qual, no caso brasileiro, as estatísticas de ensino afirmaram-se como instrumento privilegiado de orientação das políticas educacionais no contexto de centralização administrativa estabelecida pelo governo Vargas. Assim, tentou-se tecer um possível entendimento acerca da farta presença dos números nos discursos oficiais sobre educação que circularam no Brasil na década de 1940. Pretendeu-se, ainda, retomar o processo mediante o qual se constituiu no País um aparato de coleta e tratamento dos dados estatísticos, identificando-se uma estreita vinculação entre os esforços de consolidação das estatísticas demográficas nacionais e as atividades levadas a efeito no âmbito da gestão da instrução pública. Para 
tanto foram consultados materiais publicados pelo Instituto Brasileiro de Geografia e Estatística (IBGE) - que desde 1938 responde pela organização das informações demográficas oficiais no País. Assume-se, ainda, como fonte exemplar dos discursos oficiais sobre educação a Revista Brasileira de Estudos Pedagógicos, publicada desde 1944 pelo Instituto Nacional de Estudos e Pesquisas Educacionais (Inep). Completam o quadro de referências trabalhos acadêmicos de História que lançam um olhar retrospectivo a estes processos.

\section{Centralização política e organização das estatísticas de educação no Brasil}

Durante as primeiras décadas da República, evidencia-se no Brasil a firme convicção, por parte das elites republicanas, quanto à importância e urgência dos trabalhos estatísticos, sem os quais, pensava-se, não seria possível levar a bom termo as iniciativas do novo regime político. É possível perceber nos discursos das figuras públicas daquele período a defesa das estatísticas como uma ferramenta fundamental para a realização de um planejamento acertado da atuação do poder público. Heitor Eloy Alvim Pessoa, que foi do Serviço Nacional de Recenseamento, ressalta a importância dos serviços estatísticos e "sua influência na solução dos demais problemas do Govêrno, o qual, na ausência de bons registros de suas realidades e possibilidades, dirigirá como um timoneiro sem bússola a barca do Estado" (Pessoa, 1940, p. 88). Teixeira de Freitas, em artigo de 1941, dá evidências de seu entusiasmo ao afirmar que "será fácil, radiosa e bela a ascensão de nosso Brasil até essas remotas e deslumbrantes alturas se êle souber e quiser seguir o roteiro que a estatística lhe ofereceu" (Freitas, 1941, p. 99). A esse respeito afirma Lourenço Filho, cuja preocupação com as estatísticas era notável, que

[...] todo problema político se apresenta, em sua origem, como um problema de massa. Portanto, como um problema a que a estatística deve servir, primeiro, na sua descrição e na sua caracterização, depois na sua interpretação. E, se dessa interpretação, resultar a conclusão de interdependência dos fatos, a estatística passa a fornecer também os elementos de mais sadia e justa direção dos grupos sociais ou dos povos (Lourenço Filho, 1940, p. 73).

As estatísticas nesse período são consideradas como um relevante instrumento descritivo da realidade, que permitiria ver a origem dos problemas, as lacunas e as falhas na estrutura social e indicar a intervenção necessária, desempenhando, portanto, importante papel na orientação das políticas empreendidas pelo Estado brasileiro. Envoltas em legitimidade por seu estatuto científico, as estatísticas assumem a tarefa de descrever as situações com vista a identificar os pontos onde é necessária a ação política estatal.

No que concerne às estatísticas de educação, é preciso destacar que, até 1870, inexistia um órgão que fosse responsável por sua realização e organização. Em 1871 foi criada a Diretoria Geral de Estatística, cuja atribuição principal, no entanto, era a realização dos censos decenais. Ainda assim, e mesmo que secundariamente, mencionavase em seu regulamento, de modo explícito, a responsabilidade dessa Diretoria com a realização das estatísticas da instrução. Figurava entre seus objetivos a realização de levantamentos quantitativos referentes "à população, ao território, ao estado político, intelectual e moral e ao agrícola, comercial e industrial" (Franca, 1947, p. 624). Previa-se, naquela ocasião,

[...] o levantamento completo das escolas existentes no País, com discriminações relativas ao grau e à espécie, versando as indagações sôbre a constituição do professorado, a composição, por sexo, do discipulado, segundo a matrícula geral e a freqüência, esta somente em relação ao ensino primário (Pessoa, 1946, p. 257).

Porém, passado o Recenseamento de 1872, não foram providas condições para que a Diretoria levasse adiante suas outras atribuições. Pessoa (1946, p. 256) afirma a esse respeito que

[...] de pouco valia [...] criar a Diretoria Geral de Estatística e prescrever o âmbito das estatísticas que ela teria a missão de apurar e coordenar, desde que nenhuma providência fôra prevista para garantir a realização de uma boa coleta, com base na existência de fontes de informação operantes e na colaboração interessada dos Governos provinciais. 
Em vista dessas dificuldades, em 1879, a Diretoria foi desativada, sendo restaurada em 1890 pelo governo da República, porém mais uma vez sem que lhe fossem dadas condições adequadas de funcionamento. Mesmo não tendo a estatística educacional nesse período se desenvolvido muito mais do que nos momentos anteriores, o fato de esta, pela primeira vez, figurar explicitamente como objetivo e responsabilidade estatal evidencia a importância atribuída à educação entre as questões do Estado. Pessoa (1941, p. 1249) afirma que

[...] se os trabalhos dessa repartição não produziram todos os frutos esperáveis, ao menos serviram para imprimir maior regularidade aos cômputos numéricos sôbre as atividades educativas do País e para assegurar um maior interêsse pelo estudo das causas de imperfeição daqueles levantamentos.

A partir do final do Império, a estatística da instrução passa a ser uma preocupação declarada e, ao menos nos discursos, aparece como prioridade que aos poucos, e já na República, vai sendo organizada e desenvolvida.

Embora já se pudesse sentir a preocupação com a realização das estatísticas educacionais desde a segunda metade do século 19, nem o Império, em toda sua duração, nem a República, nos seus primeiros anos, conseguiram dar conta de organizálas. Essa situação incomodava a algumas figuras públicas, que, mesmo não tendo conseguido solucionar as lacunas e anular as dificuldades, em vários momentos, responderam por tentativas de reverter esse quadro. Franca (1947, p. 625) afirma que, a respeito da escassez de estatísticas educacionais, "os reclamos dos nossos homens mais esclarecidos vinham-se fazendo ouvir insistentemente", de modo que se alternaram períodos de intensa atividade, devido ao interesse e à preocupação desses homens, e outros de estagnação, por ocasião das dificuldades de ordem prática e, sobretudo, pela falta de recursos financeiros. Várias tentativas de organização das estatísticas educacionais foram feitas e, ainda que esparsamente, vinham sendo realizados alguns levantamentos regionais acerca da instrução, "entretanto, o que se havia feito carecia de ordem, clareza, uniformidade. Havia, enfim, elementos, ora de alguns Estados, ora de outros e nunca uma estatística completa de todo o País" (Franca, 1947 , p. 625). Com vista a solucionar esses problemas, a Diretoria procurou empreender algumas iniciativas sem que, no entanto, obtivesse êxito na organização das coletas regionais e sistematização dos dados obtidos. De um lado porque não havia, por parte dos Estados, muita colaboração; a maioria deles não respondia aos apelos da Diretoria para que lhe mandassem dados educacionais, e os poucos que promoviam levantamentos regionais e os enviavam ao órgão central o faziam de forma assistemática ou, em outros casos, com dados incompletos e pouco confiáveis. Por outro lado, a Diretoria não contava com estrutura suficiente para ela própria realizar os levantamentos em cada região, o que lhe permitiria prescindir da colaboração dos Estados. Além disso, a Diretoria tinha por atribuição organizar também as estatísticas de outros setores, o que representava uma insustentável divisão de esforços. Desse modo, pouco se avançou no que se refere à organização das estatísticas escolares nas primeiras décadas da República.

Apenas sob o comando centralizador do governo Getúlio Vargas foi possível organizar os trabalhos demográficos sistemáticos que se afirmava serem necessários ao País. Levado ao poder pelo movimento que se convencionou chamar de "Revolução de 30", Vargas manteve-se na presidência da República entre 1930 e 1945. Nesse período, a centralização do poder nas mãos do governo federal, personificado no próprio chefe de Estado, destaca-se como característica principal na condução das questões políticas. Skidmore (2000, p. 55-56) afirma que "o governo federal aumentava seus poderes na esfera administrativa por dois modos diferentes. Primeiro, muitas funções, previamente exercidas por governos estaduais e municipais, foram transferidas para a área de competência federal"; em segundo lugar, "a crescente intervenção federal, notadamente na economia, requeria novos órgãos federais, os quais, em retorno, enfraqueciam ainda mais o poder relativo dos Estados e municípios". Assim, nesse período assiste-se à criação de diversos órgãos associados à União que tinham por atribuição normatizar e controlar as ações dos estados brasileiros a partir de diretrizes fixadas por uma instância central de decisões. Nessas circunstâncias são criados o Ministério da Educação e Saúde (em 1930) e o Inep (em 
1937), com a finalidade de regular e conduzir as questões educacionais, e o IBGE (em 1938), responsável pela organização das estatísticas brasileiras em âmbito nacional.

Com a criação do Ministério da Educação e Saúde, as estatísticas educacionais ganham novo impulso e mais uma vez alimenta-se a esperança de organizá-las nacionalmente. Entre as principais preocupações presentes nos anos que se seguiram à organização desse Ministério estava o levantamento dos números sobre o ensino. Acreditava-se que, para que o novo órgão pudesse levar a efeito os objetivos para os quais havia sido criado, era imprescindível a obtenção de dados que permitissem conhecer a situação na qual se encontrava a educação do País naquele momento. Teixeira de Freitas informa que, em mensagem dirigida aos chefes dos governos regionais em novembro de 1932, o presidente da República Getúlio Vargas ressaltava que

[...] o assentamento de um plano orgânico e suficientemente amplo, de medidas governamentais, em que estreitamente cooperem as três linhas de força de nossa estrutura política, não será possível enquanto o País não conhecer exatamente, isto é, com atualidade, minúcia e verdade, o alcance da obra educacional que já se realiza, suas falhas, suas possibilidades e toda a extensão do esforço que ainda precisa empregar tendo em vista nossas profundas diferenciações geográficas e sociais (apud Jardim, 1941, p. 1100).

Getúlio Vargas reforçava ainda que esse conhecimento só poderia "ser obtido através de estatísticas rigorosas e suficientemente compreensivas, que até agora não tínhamos ainda podido organizar, devido principalmente à falta de cooperação entre o Governo Federal e os governos regionais" (idem). No ano seguinte à criação do novo Ministério foi instituída, no conjunto das diretorias que davam forma ao órgão responsável pela educação e saúde do País, a Diretoria Geral de Informações, Estatística e Divulgação; era a primeira vez que no Brasil se criava um órgão cuja atribuição principal era tratar das estatísticas educacionais. Pouco tempo depois essa Diretoria passou a chamar-se Serviço de Estatística de Educação e Saúde (Sees). Subordinado administrativamente ao Ministério de Educação e tecnicamente ao Instituto Brasileiro de Geografia e Estatística (IBGE), o Sees tinha a tarefa de "levantar e coordenar a estatística geral das atividades educacionais, culturais e médico-sanitárias do País, bem como prover à respectiva divulgação" (Franca, 1947, p. 633).

Criado em 1937, o Inep ${ }^{1}$ passou a dividir - e, em alguns casos, disputar - espaço com o Sees na produção e análise das estatísticas do ensino. Na exposição de motivos para sua criação, Gustavo Capanema enfatizava a necessidade de que o País tivesse um "aparelho central destinado a inquéritos, estudos, pesquisas e demonstrações, sobre os problemas do ensino, nos seus diferentes aspectos" (apud Lourenço Filho, 1964, p. 11). Desfrutando da imagem de neutralidade e objetividade, pelos procedimentos técnicos que utilizava nas pesquisas que desenvolvia, este novo centro de estudos tinha por atribuição, entre outras coisas, produzir conhecimento considerado imparcial e racional que serviria à correta condução das ações do poder central, entre as quais figuravam os levantamentos quantitativos sobre instrução. ${ }^{2}$ À parte a produção de seus próprios inquéritos estatísticos, ao Inep coube, ainda, a análise e interpretação dos dados fornecidos pelo Sees. De acordo com Jardim (1945, p. 229), "o Sees encarrega-se de fazer a síntese geral e divulgar 'em bruto' as estatísticas concluídas que o IBGE e o Ministério da Educação também publicam; e o Inep procede à análise minuciosa e a comparações sucessivas dos resultados dessas estatísticas".

O envolvimento do Inep nas atividades de produção e circulação das informações quantitativas sobre educação explica a significativa presença de estatísticas no periódico de sua responsabilidade, qual seja, a Revista Brasileira de Estudos Pedagógicos, que neste texto foi tomada como fonte exemplar dos discursos educacionais oficiais que circularam no Brasil na década de $1940 .^{3}$ Não se pretende, evidentemente, proceder a uma análise exaustiva dessas formulações discursivas - para o que seria necessário investigar outras fontes - , mas apenas ilustrar o discurso característico daquelas figuras envolvidas nas questões de Estado. Vale ressaltar, portanto, que os discursos aqui examinados são em grande parte expressão do ideário do Estado brasileiro, visto que, mesmo quando não foram escritos pelas próprias figuras públicas ligadas às ações de governo, receberam autorização para divulgação num periódico em que é evidente - naquele momento - a intenção de propaganda laudatória das ações governamentais.

\footnotetext{
${ }^{1}$ Este órgão foi criado através da Lei $\mathrm{n}^{\circ} 378$, de 15 de janeiro de 1937, como Instituto Nacional de Pedagogia. Sua efetiva instalação ocorreu, porém, apenas no ano seguinte, em 30 de julho de 1938, tendo sido seu nome alterado para Instituto Nacional de Estudos Pedagógicos (Inep), pelo Decreto-Lei ${ }^{\circ} 580$, e modificadas suas competências e organização. Em 1972 passou a chamar-se Instituto Nacional de Estudos e Pesquisas Educacionais, mantendo, contudo, a mesma sigla.

2 Sobre a história do Inep numa perspectiva que busca explicitar as características assumidas pelas pesquisas e demais ações do órgão em função das pessoas, das idéias e dos interesses envolvidos nas atividades de direção do instituto, ver: Saavedra, 1988.

3 instituto, ver: Saavedra, 1988. curso educacional produzido pelos autores de artigos publicados na Revista Brasileira de Estudos Pedagógicos que busca evidenciar as principais tendências do pensamento intelectual no periódico e seu envolvimento como Estado encontra-se em Gandini, 1995.
} 
Assim, devido à importância do Inep na orientação das políticas educacionais e pelo papel atribuído à sua Revista na divulgação das informações consideradas relevantes para a adequada condução das questões estatais, é que o estudo aqui apresentado assume esse periódico como fonte privilegiada de percepção dos modos pelos quais se organizaram os discursos oficiais no período considerado.

Antes, no entanto, que se proceda à análise da presença das estatísticas no discurso estatal, é preciso mencionar a relevância do Instituto Brasileiro de Geografia e Estatística (IBGE) no âmbito das produções demográficas brasileiras. Com a reformulação administrativa procedida pelo governo Vargas, também no que se refere à produção das estatísticas gerais, foi instituída a centralização dos serviços federais em um único órgão. Nos primeiros anos da década de 1930, a estatística educacional já havia logrado consideráveis avanços no que se refere à padronização dos dados numéricos por intermédio do Convênio Interadministrativo das Estatísticas Educacionais e Conexas, firmado em 1931. Motivado por esta experiência bem sucedida, o ministro da Educação e Saúde, Francisco Campos, apresentou um projeto de racionalização das diversas estatísticas de interesse nacional mediante a criação de um Instituto Nacional de Estatística e Cartografia que viesse a estabelecer um sistema coordenado dos trabalhos federais e regionais. Esse foi, de certo modo, o anteprojeto da criação do Instituto Nacional de Estatística - depois chamado de Instituto Brasileiro de Geografia e Estatística (IBGE) - , tendo sido analisado por vários especialistas da área e tomado como ponto de partida para a configuração de uma proposta de profunda reforma do sistema das estatísticas nacionais. A preocupação naquele momento não estava na mera realização de novos levantamentos populacionais ou trabalhos estatísticos sobre algum aspecto específico; pensava-se em organizar um sistema nacional de estatísticas que desse conta de coordenar esforços e definir responsabilidades com o intuito de pôr termo à instabilidade na qual, até então, tinham estado as iniciativas no âmbito da estatística brasileira. A partir da análise da proposta encaminhada pelo ministro da Educação e Saúde foi criado o Instituto Nacional de Estatística. No documento de criação deste Instituto considerava-se
[...] a conveniência de estabelecer, de modo permanente e sistemático, a coordenação de todos os serviços estatísticos de interêsse geral, já existentes ou que vierem a existir nas várias esferas e dependências da administração pública ou em instituições privadas (Decreto ${ }^{\circ} 24.609$ apud Revista Brasileira de Estatística, 1940, p. 150).

Em 1937, veio incorporar-se ao sistema o Conselho Brasileiro de Geografia, através do Decreto ${ }^{\circ} 1.527$, constituindo-se, assim, "um organismo de dupla projeção, praticamente responsável pela superior orientação de todos os serviços de que depende o progresso da geografia humana no Brasil" (Pessoa, 1940, p. 99), quais sejam, a estatística e a cartografia. Em 1938, através do DecretoLei ${ }^{\circ} 218$, integraram-se o Instituto Nacional de Estatística e o Conselho Brasileiro de Geografia em um único órgão denominado Instituto Brasileiro de Geografia e Estatística (IBGE). Desse modo,

[...] passou o País a contar com a organização eficiente, constituída de tríplice sistema de serviços - geográficos, estatísticos e censitários - , que lhe facultaria a execução regular das investigações que se fizessem necessárias ao exato conhecimento do território e das atividades nacionais, assegurada, em benefício dos objetivos comuns, a coordenação dos vários setores de trabalho (IBGE, 1950, p. xii).

\section{As estatísticas nos discursos oficiais sobre educação}

Conforme já fora mencionado, nas primeiras décadas da República, no Brasil, considerava-se que os números sobre a situação escolar brasileira, ao comporem um "retrato" do que se passava na área de educação, serviriam para orientar as ações adequadas a serem empreendidas pelo Estado. Devia-se a esta crença a farta presença de dados estatísticos educacionais e de artigos que analisavam essas informações ou, simplesmente, as reproduziam como forma de ilustrar a situação do ensino no País, na Revista Brasileira de Estudos Pedagógicos, periódico do Inep de cujas atribuições constava a orientação das políticas públicas educacionais.

As estatísticas que figuram nos artigos publicados na Revista nos anos de 1940 são apresentadas quase sempre como um instrumento capaz de revelar sem enganos a 
realidade dos fatos. Não se mencionava naquele periódico a inerente relatividade das estatísticas. Não se colocava em questão o fato de que, mesmo se fosse possível anular todas as dificuldades de coleta e tratamento dos dados, os números não apresentariam por isso uma "verdade" mais nítida e completa. A discussão em foco referia-se à busca da perfeição do retrato, e não aparece nos discursos que circularam na Revista no período analisado menção à compreensão de que qualquer conjunto de informações refere-se a uma escolha entre tantas possíveis que, portanto, pode mostrar "retratos" diferentes dos que seriam apresentados se a escolha fosse outra. Nos artigos examinados os autores referem-se aos conhecimentos científicos, incluindose as estatísticas, como expressão da "verdade" dos fatos, a menos que seus modos de produção fossem falhos. Vale ressaltar que a ausência de discussão sobre as limitações das estatísticas não nos pode levar a concluir que tais intelectuais as desconhecessem. Alguns dos mesmos autores, quando escrevem na Revista Brasileira de Estatística, do IBGE, travam longos debates em torno das discordâncias e acordos sobre o alcance das interpretações advindas dos dados estatísticos. Na Revista Brasileira de Estudos Pedagógicos, porém, as ressalvas feitas aos números são quase sempre atribuídas às falhas no sistema de obtenção e sistematização das informações e predomina a idéia das estatísticas como retrato ou tradução da realidade. Assim, quando Teixeira de Freitas (1946, p. 211) alerta para a necessidade de "distinguir, nos resultados da estatística, a situação aparente e a situação real" não está se referindo às limitações das estatísticas em si, mas, antes, explicitando uma situação de inadequada obtenção de informações. Diante dessa concepção, os dados demográficos adquiriam contorno peremptório, recebendo a atribuição de desvelar a "imagem" verdadeira acerca da sociedade. É por estarem imbuídas desse poder "revelador" que as estatísticas passam a ser consideradas imprescindíveis na atividade de gestão pública.

$\mathrm{O}$ fato de que em muitos dos discursos publicados no periódico não sejam mencionadas as fontes dos dados é indicativo da pouca preocupação que se tinha naquele momento com relação à explicitação dos modos de produção das informações. A ausência de referências procede a um movimento de "naturalização" dos números, uma vez que se omite o fato de que estes foram produzidos em condições e por instituições determinadas. Opera-se, assim, com a idéia de que as estatísticas são objetivas, sem margem para discussão acerca das circunstâncias de sua produção e das metas às quais se prestam; desse modo, considera-se que não é necessário nem mesmo indicar de onde provêm. Tal situação é encontrada principalmente nos Editoriais do periódico onde os algarismos, que constróem uma condição propícia ao elogio das ações governamentais, não são acompanhados da indicação da fonte que os originou. No entanto, como os Editoriais expressavam as opiniões e divulgavam as iniciativas empreendidas pelo Ministério da Educação e Saúde e pelo Inep, fica suposto que, por se referirem ao sistema oficial de ensino, as estatísticas de que se valem também sejam oficiais. Nos artigos presentes em outras seções da Revista, quando se indicam as fontes informantes, são fartas as referências aos dados do Recenseamento da população brasileira realizado em 1940 - ainda que esta não seja a única fonte mencionada nos discursos examinados. Poucas eram as perguntas dos censos que versavam sobre educação, porém estas foram amplamente analisadas e debatidas, sobretudo devido ao fato dos índices de analfabetismo apurados terem sido considerados altos pelos educadores e administradores públicos da época.

Assim, entre os temas predominantes nos discursos educacionais que se utilizam de estatísticas oficiais destacam-se as discussões sobre analfabetismo que ocuparam vários artigos da Revista sobretudo após 1947, quando o governo federal iniciou a Campanha de Educação de Adultos. Também são recorrentes a descrição e a análise da organização e do movimento do ensino primário. Apesar de existirem alguns trabalhos sobre os níveis secundário e superior, estes são mais raros na publicação. Percebe-se que a maior preocupação era com o nível elementar, que não apenas se mostrava insuficiente para atender a demanda potencial de crianças em idade de freqüentar a escola, como também apresentava problemas de fluxo em vista dos altos índices de reprovação e evasão escolar. Ainda no que se refere ao nível primário, destacava-se a inquietação acerca da escassez de prédios escolares para atender as crianças da zona rural e, em menor proporção, a falta de escolas normais. Encontram-se ainda alguns artigos que se utilizam dos números para 
explicitar o movimento relativo ao financiamento do ensino. Nesses casos, as cifras servem, de certo modo, a uma prestação de contas acerca do orçamento e das despesas em educação.

As informações estatísticas oficiais presentes nos artigos publicados no período que se está considerando cumprem, de modo geral, três propósitos básicos. Tal distinção é apenas esquemática, visto que as funções dos números, identificadas a partir da análise desses discursos, são complementares e muitas vezes podem ser percebidas num mesmo artigo. Era comum que as estatísticas se prestassem simplesmente a descrever o movimento educacional dos Estados; era também recorrente a utilização de estratégias discursivas que punham em relevo, pelo contraste dos números, os progressos da escola brasileira. Havia, ainda, nos textos que se ocupavam de divulgar o que se fazia em benefício da educação nas unidades federadas e na União, o uso dos dados numéricos para uma discreta propaganda laudatória das ações do poder público.

Nos artigos em que se destaca a descrição da situação do ensino, a presença dos números era, em geral, abundante, compondo um quadro minucioso acerca da estrutura escolar e do movimento do ensino. As informações estavam, na maior parte das vezes, organizadas em tabelas e listas, mas também podiam ser encontradas incorporadas ao corpo do texto. Era freqüente a coexistência de descrições qualitativas e quantitativas acerca dos sistemas escolares, nas quais as estatísticas assumiam papel relevante na indicação da magnitude da educação nacional. Em grande parte dos casos em que as informações numéricas propunham-se a apenas descrever o ensino, os dados apresentados buscavam dar visibilidade à educação das distintas regiões do País, isoladas pelas enormes distâncias territoriais e pelas dificuldades de comunicação da época. Assim, acabava-se por criar um quadro informativo sobre a educação dos Estados brasileiros que punha em relevo seus modos de organizar o sistema escolar, permitindo comparações e destacando as localidades que, no que se refere à questão da instrução popular, apresentavam situações modelares. Sob pretexto de apenas informar de modo "objetivo" a realidade educacional dos Estados, os dados são, muitas vezes, apresentados sem comentários adicionais e conformam um quadro em que cada região ocupa diferente posição numa escala de prestígio que se define de acordo com o êxito - evidenciado, principalmente, pela maior quantidade de escolas, matrículas e conclusões de curso e pelas menores taxas de analfabetismo e repetência escolar - na condução das questões administrativas da instrução pública. Constrói-se, recorrendo-se aos números, uma vitrine da educação nos Estados em que é possível não apenas conhecer a realidade de cada lugar, mas, principalmente, comparar os desempenhos dos governos regionais na gestão do ensino.

Eram também comuns nos discursos educacionais na década de 1940 as comparações entre números oficiais de diferentes períodos como estratégia de se explicitar a evolução quantitativa da educação. Vários artigos utilizavam-se de uma estratégia discursiva através da qual se objetivava evidenciar os progressos educacionais relacionando números referentes a diferentes épocas da história do País. Partindo-se de uma breve retrospectiva histórica, pretendiase contrapor o passado educacional, descrito de modo desfavorável, com os acontecimentos e as iniciativas recentes. Nesses casos, quase sempre o intuito de mostrar os progressos do ensino articulava-se a uma certa propaganda laudatória das ações do poder público. Nessas circunstâncias, ao lado da exposição dos problemas da educação nacional encontram-se referências positivas às iniciativas do governo federal, do Inep e da própria Revista. Os algarismos indicavam o quanto vinha o governo empreendendo na área educacional com vista à melhoria das péssimas situações descritas. De modo geral, nestes casos, os números são relevantes para a argumentação à medida que explicitam as circunstâncias que motivaram a ação que está sendo noticiada ou, em outros casos, são cruciais para construir uma imagem da situação precária do ensino nacional dando expressão à denúncia formulada. Freqüentemente tais informações são também evocadas para ilustrar as necessidades educacionais, indicando quanto ainda precisava ser feito. Essas informações dimensionavam a situação difícil do ensino brasileiro em termos quantitativos preparando uma compreensão positiva da atuação governamental que se envolve de certo heroísmo pelo contraste com os dados precedentes.

Investigar a presença das estatísticas do ensino nos discursos oficiais sobre educação articula-se ao intuito de compreender os modos pelos quais a busca da modernidade 
educativa conferiu às informações científicas a atribuição de adequadamente conduzir a administração da instrução popular. Ao longo dos anos das décadas de 1920 e 1930, os intelectuais brasileiros alimentaram a confiança em que seria possível modificar a sociedade pela via da renovação educacional. Acreditava-se que a ciência apontaria as ações realmente necessárias substituindo a tomada de decisões pautada pelas vontades do governante, entendendo-se a política como uma competência essencialmente técnica. Assim, o recurso às estatísticas acabou por figurar no quadro das preocupações da burocracia oficial como um instrumento precioso, porque imbuído de racionalidade, para a legitimação das decisões tomadas na esfera pública. Percebe-se no exame dos discursos que recorrem aos números do ensino uma construção argumentativa tal que põe em destaque a necessidade das ações empreendidas pelo poder público, à medida que as cifras evidenciam as lacunas da educação nacional. Ressalta-se também a acentuada recorrência às afirmações de progresso, que se coadunavam ao discurso otimista em voga no período a partir do qual se afirmava estar o País a caminho de um futuro promissor. Desse modo, os números educacionais colaboravam na construção da imagem do progresso nacional, mediante o contraste de informações recentes com algarismos mais antigos, ao mesmo tempo em que ratificavam a idéia de que estava em pleno movimento a busca da modernidade.

\section{Referências bibliográficas}

ALMEIDA JUNIOR. O excesso de escolas normais no estado de São Paulo. Revista Brasileira de Estudos Pedagógicos, Rio de Janeiro, v. 9, n. 24, p. 46-51, set./out. 1946.

DECRETO no 24.609, de 6 de julho de 1934. Revista Brasileira de Estatística, Rio de Janeiro, v. 1, n. 1, p. 150-161, jan./mar. 1940.

DEPARTAMENTO ESTADUAL DE ESTATÍSTICAS DE SÃO PAULO. O ensino secundário e normal no estado de São Paulo em 1946. Revista Brasileira de Estudos Pedagógicos, Rio de Janeiro, v. 11, n. 30, p. 293-306, set./out. 1947.

FRANCA, José Quadros. A estatística educacional no Brasil. Revista Brasileira de Estatística, Rio de Janeiro, n. 30-31, p. 624-634, abr./set. 1947.

FREITAS, M. A. Teixeira de. A estatística e a organização nacional. Revista Brasileira de Estatística, Rio de Janeiro, n. 5, p. 90-105, jan./mar. 1941.

. Formação do homem brasileiro como trabalhador e cidadão da democracia. Revista Brasileira de Estudos Pedagógicos, Rio de Janeiro, v. 7, n. 20, p. 185-222, fev. 1946.

GANDINI, Raquel. Intelectuais, Estado e Educação: Revista Brasileira de Estudos Pedagógicos 1944-1952. Campinas: Ed. Unicamp, 1995.

GIL, Natalia de Lacerda. Razão em números: a presença das estatísticas nos discursos educacionais divulgados na Revista Brasileira de Estudos Pedagógicos (1944-1952). 2002. Dissertação (Mestrado) - Faculdade de Educação da Universidade de São Paulo, São Paulo, 2002.

IBGE. Censo demográfico - população e habitação. V Recenseamento Geral do Brasil (1940). Rio de Janeiro: Serviço Gráfico do IBGE, 1950.

JARDIM, Germano. A coleta da estatística educacional (III). Revista Brasileira de Estudos Pedagógicos, Rio de Janeiro, v. 4, n. 11, p. 229-250, maio 1945. 
JARDIM, Germano. A missão do órgão estatístico da educação e saúde. Revista Brasileira de Estatística, Rio de Janeiro, n. 8, p. 1045-1118, out./dez. 1941.

LOURENÇO FILHO, M. B. Antecedentes e primeiros tempos do Inep. Revista Brasileira de Estudos Pedagógicos. Rio de Janeiro, v. 42, n. 95, p. 9-17, jul./set. 1964.

. Estatística e educação. Revista Brasileira de Estatística, Rio de Janeiro, n. 1, p. 6685, jan./mar. 1940.

PESSOA, Heitor Eloy Alvim. A cooperação disciplinada e os recentes progressos da estatística no Brasil. Revista Brasileira de Estatística, Rio de Janeiro, n. 1, p. 86-99, jan./mar. 1940.

A estatística escolar em 1907. Revista Brasileira de Estatística. Rio de Janeiro, v. 2, n. 8, p. 1247-1258, out./dez. 1941.

. A estatística educacional no Brasil. Revista Brasileira de Estatística, Rio de Janeiro, n. 26, p. 255-260 abr./jun. 1946.

REVISTA BRASILEIRA DE ESTATÍSTICA. Rio de Janeiro, IBGE, n. 1-64, 1940-1955.

REVISTA BRASILEIRA DE ESTUDOS PEDAGÓGICOS. Rio de Janeiro/Brasília, Inep, n. 1-184, 1944-1995.

SAAVEDRA, Silvia Maria Galliac. Passos e descompassos de uma instituição de pesquisa educacional no Brasil: a realidade do Inep. 1988. Dissertação (Mestrado) - Faculdade de Educação da Universidade de Brasília, Brasília, 1988.

SKIDMORE, Thomaz E. Uma história do Brasil. 3. ed. São Paulo: Paz e Terra, 2000.

Natalia de Lacerda Gil, mestre em Educação pela Faculdade de Educação da Universidade de São Paulo (USP), é doutoranda em Educação nessa universidade e professora do curso de Pedagogia da Faculdade Sumaré, São Paulo (SP).

natalia.gil@uol.com.br

\section{Abstract \\ The importance of the statistics as an instrument in the construction of the educational modernity} in Brazil - the 1930's and the 1940's

This article aims at retrieving the process by which the educational statistic data were defined as a privileged tool for the orientation of Brazilian educational policies, during Vargas government. In order to that, the initiatives to build a national apparatus of educational statistics collection and analysis were put together, and the functions of the figures at the speeches during the period analysed were described.

Keywords: history of education; educational statistics; periodic press; educational speech.

Recebido em 2 de março de 2005.

Aprovado em 26 de agosto de 2005. 